\title{
PRAZER, SOFRIMENTO E SAÚDE MENTAL NO TRABALHO DE TELEATENDIMENTO
}

\section{1- Ana Magnólia Bezerra Mendes \\ Universidade de Brasília - UnB \\ anamag.mendes@gmail.com}

\section{3- Carla Faria Morrone}

Universidade de Brasília - UnB

carla@katanka.com.br

\author{
2- Adriana Pinho Vieira \\ Universidade de Brasília - UnB \\ adriana@alfa.br
}

Diego Maganhotto Coraiola - Editor

\section{RESUMO}

O presente artigo apresenta estudo de caráter descritivo e explicativo, realizado com o objetivo de investigar a saúde de teleatendentes, sob o arcabouço teórico da psicodinâmica do trabalho. São investigados riscos de adoecimento, vivência de prazer e de sofrimento no trabalho. O estudo foi realizado em uma central de atendimento de telefonia, conduzido por meio da abordagem metodológica quantitativa e qualitativa. $\mathrm{Na}$ etapa quantitativa, participaram 396 teleatendentes; foram utilizadas a Escala de Prazer-Sofrimento no Trabalho - EPST e a Escala de Sintomas Relacionados ao Trabalho - ESRT. Na etapa qualitativa, foram realizadas duas entrevistas coletivas semi-estruturada com nove teleatendentes. Os resultados indicam vivências moderadas de prazer-sofrimento e correlação entre sofrimento e sintomas físicos e psicológicos. As entrevistas coletivas revelaram cinco categorias síntese "O atendimento é sempre a mesma coisa, a gente vai enfadando"; "A empresa não tem a preocupação de fidelizar os funcionário"; "O que é imprevisível é o temperamento do cliente"; "O que motiva a gente é encontrar os colegas de trabalho"; Depois que eu entrei aqui, é direto dor de cabeça". Constata-se que os teleatendentes vivenciam prazer e sofrimento, que a rigidez da organização do trabalho, as precárias condições de trabalho e a ambivalência da relação com o cliente favorecem sofrimento e riscos de adoecimento. $\mathrm{O}$ sofrimento é enfrentado por meio do uso de estratégias defensivas e de compensação. Os dados evidenciam que este trabalho pode resultar em mais prejuízos físicos e psicológicos do que sociais.

\section{Palavras-Chave}

Prazer-sofrimento, saúde, riscos de adoecimento, estratégias de mediação, teleatendimento.

\section{ABSTRACT}

This study, a descriptive and explanatory one, investigates the health of telesales at work, by the supported of the psychodynamic approaching. It investigates the suffering, the pleasure and the sickness risks of the workers in confrontation with service context. The study was made in a customer service of telecommunications' company being led through a quantitative and qualitative approaching. In the quantitative stage 396 workers participated. Were used two scales - SSPW (Scale of Suffering-Pleasure in the Work) and SSRW (Scale of Symptoms Related to Work). In the qualitative stage were made 02 semi-structured interviews in group with 09 telesales workers. The quantitative results indicates moderate existences of suffering-pleasure with the prevalence of existence pleasure. The physical symptoms and psychosocial are inside the average. The interviews in groups indicated five synthesis categories: "The attendance is always the same thing, we are getting tired"; "The company doesn't have concerns about the employees"; "What is unexpected is the customer's temper"; "what motivates us, besides needs is finding the co-workers"; "After I started here, I always have headache". Based on the data was possible to verify that the telesales live suffering and pleasure, that the company's rigidity, allied to precarious working conditions favors the suffering, exposing the workers to run the risk of getting sick. The suffering is faced through the use of defensive and compensation strategies. This data shows that this job can result more psychological and physical damage then socials ones.

Keywords

Suffering-pleasure, health, sickness risks, mediation strategies, telesales. 


\section{Introdução}

O atual contexto do trabalho, fruto da permanente instabilidade do mercado de trabalho e de 1obra, pela degradação do trabalho, pela desestabilização e pela desestruturação das relações socioprofissionais, propiciou um cenário no qual o sofrimento psíquico, as descompensações psíquicas e somáticas, os acidentes de trabalho e o adoecimento físico e psíquico dos trabalhadores se tornaram presentes (DEJOURS, 1999). Paralelamente, a migração significativa da oferta de emprego do setor de indústria para o setor de serviços, dentre os quais se destacam os serviços de teleaendimento, fez emergir, como aponta Zarifian (2001), um símbolo contemporâneo da expansão do taylorismo nas organizações. As centrais de atendimento, objeto do estudo apresentado neste artigo, apresentaram no Brasil, nos últimos três anos, segundo a Associação Brasileira de Telemarketing, crescimento equivalente a $235 \%$. Criadas com a finalidade de executar serviços de telemarketing de empresas, exclusivamente por telefone, abarcando, em sua metodologia de trabalho, sistemas de telecomunicação e de informática e múltiplas mídias para padronização dos atendimentos, têm sido apontadas como forma moderna de degradação das condições de trabalho e do emprego em decorrência da natureza taylorista do trabalho e de algumas características inerentes ao processo de trabalho, tais como estresse, trabalho penoso e precário, baixa remuneração, fraca proteção jurídica e flexibilização da mão-de-obra (BUSCATTO, 2002).

O significativo aumento do número de centrais telefônicas no Brasil e o número incipiente de estudos sobre esta forma de trabalho à luz do arcabouço teórico da psicodinâmica do trabalho pautaram a realização deste estudo, pelo qual buscou-se aprofundar a análise da saúde psíquica dos trabalhadores de teleatendimento, relacionando-a às características da organização do trabalho, das condições de trabalho e das relações socioprofissionais.

\section{Referencial Teórico}

Segundo a psicodinâmica, o trabalho exerce papel fundamental na estruturação da saúde psíquica de um indivíduo, quando the permite diminuir a sua energia pulsional; no entanto, quando não possibilita a descarga pulsional, tornase fatigante, fonte de adoecimento (DEJOURS, 2004). Sob a ótica da psicodinâmica, o trabalho, um dos meios pelo qual se constrói a identidade do trabalhador no campo social, pode ser fonte de prazer ou de sofrimento psíquico, sendo, a saúde psíquica de um individuo determinada, dentre outros fatores, pela vivência de prazer no trabalho e pelo resultado das tentativas bem sucedidas de transformação das situações adversas, presentes no contexto de trabalho, em um modo contínuo de busca do prazer e de evitação do sofrimento pelo enfrentar das imposições e das pressões do trabalho que causam instabilidade psicológica. $\mathrm{O}$ processo de adoecimento, por sua vez, é resultado da presença continua e intensa de sofrimento psíquico sem êxito de enfrentamento, originado pela não realização de desejos em decorrência do confronto com uma cultura de padronização, de restrição e homogeneização de comportamentos, que inviabiliza os ajustes necessários à expressão da autenticidade do trabalhador.

O trabalho tornar-se fonte de prazer quando os trabalhadores vivenciam uma dinâmica de reconhecimento do trabalho ou quando conseguem transformar situações causadoras de sofrimento em vivências de prazer e conseqüentemente de saúde, pelo emprego de mecanismos tais como os de mobilização subjetiva ou coletiva; ou tornar-se fonte de sofrimento quando inviabiliza a realização dos desejos psíquicos do indivíduo trabalhador. A presença de sintomas físicos ou psicossociais retrata a incompatibilidade dos trabalhadores em lidarem com a satisfação de suas demandas individuais em detrimento ao contexto de trabalho.

Para a psicodinâmica, a saúde psíquica não é decorrência da ausência de sofrimento, mas sim da existência de possibilidades internas e externas capazes de propiciarem ao trabalhador meio de transformação do sofrimento pela tomada de consciência de suas causas, dos seus conflitos e das situações que o geraram (MENDES, 2004). O trabalho deve favorecer a modificação do sofrimento e não a sua eliminação, pois, quando transformado em criatividade, o sofrimento contribui beneficamente para a construção da identidade do indivíduo e para o aumento da resistência ao risco de desestabilização psíquica e somática, atuando, assim, como mediador de saúde. No entanto, o sofrimento psíquico, quando derivado de um trabalho descaracterizado da sua função de estruturante psíquico, sinaliza a existência de choque entre o trabalho e as aspirações e desejos do indivíduo bem como o emprego, pelo trabalhador, de todos os seus recursos intelectuais, psicoafetivos, de aprendizagem e de adaptação para conter o sofrimento. Pesquisas, como a conduzida por Mendes et al (2005), revelam que o sofrimento psíquico manifesta-se por meio da vivência concomitante de esgotamento mental 
expressa pelos sentimentos de insegurança, inutilidade, desqualificação, desgaste e estresse; e de falta de reconhecimento do trabalho expressa pelos sentimentos de injustiça, indignação e desvalorização pelo não reconhecimento do trabalho.

Pela perspectiva da psicodinâmica, um dos modos de enfrentamento da realidade permeada pelo sofrimento no trabalho realiza-se pela utilização de estratégias defensivas individuais regras de condutas criadas pelo indivíduo, de acordo com as situações de trabalho, que lhe permite enfrentar o sofrimento sem se abater - e/ou coletivas - estratégias construídas pelo grupo de trabalho, por um acordo tácito entre todos os membros, que possibilitam a manutenção do pseudoequilibrio; expressas sob diferentes formas tais como mentiras, dissimulações, violências, manifestações de desesperança, desprezo. Segundo Mendes (1996), estas defesas permitem, por um lado, a convivência com o sofrimento e, por outro, um processo de alienação das verdadeiras causas do sofrimento, processo que possibilita à ideologia dominante, além de explorar e utilizar o próprio paradoxo das defesas para evitar discussões sobre a organização do trabalho, manter os trabalhadores produtivos, alheios às causas dos seus próprios sofrimentos. O uso exacerbado de defesas pode culminar no esgotamento do trabalhador, abrindo caminho para $\mathrm{o}$ adoecimento.

Como constructo dialético, o sofrimento no trabalho pode ser patogênico - quando há bloqueio da relação subjetiva com a organização do trabalho por não ser mais possível adaptações ou ajustes a essa - e criativo - quando há a possibilidade de transformação do sofrimento que passa, como mediador de saúde, a propiciar a formação da identidade e a evitar a desestabilização psíquica somática. O prazer, por sua vez, tanto pode ser alcançado pela ressignificação do sofrimento e pela transformação do contexto de trabalho, como também pelo resultado direto do trabalho, quando existe compatibilidade entre necessidades e desejos do trabalhador e a organização do trabalho. Além disso, a obtenção do prazer pode derivar-se do mecanismo de mobilização subjetiva, processo pelo qual os trabalhadores lançam mão dos seus recursos intelectuais, da sua subjetividade para transformar as situações causadoras de sofrimento em de prazer, possibilitando o resgate do sentido do trabalho. Ferreira e Mendes (2003) reformulam conceitualmente a estratégia de mobilização subjetiva, propondo a estratégia de mobilização coletiva, mecanismo que realça aspectos socioculturais e coletivos, em particular a cooperação. Segundo os autores, a mobilização coletiva refere-se ao modo de agir de um grupo de trabalhadores empregado para ressignificar o sofrimento, fazer a gestão das contradições do trabalho e transformar em fonte de prazer o contexto de trabalho. Viabiliza-se pelo espaço público de discussão e pela cooperação entre os trabalhadores. Por fim, a dinâmica do reconhecimento permite surgir um processo de reapropriação que extrapola o processo de resistir ao sofrimento e ao adoecimento, ao possibilitar aos trabalhadores a construção de saúde. Para que o trabalho opere como fonte de saúde há a necessidade do reconhecimento daquele que trabalha, uma vez que no reconhecimento reside a possibilidade de dar sentido ao sofrimento vivenciado pelos trabalhadores. O reconhecimento das contribuições realizadas pelo trabalhador pode ocorrer tanto pelas constatações feitas pelo grupo de trabalho, hierárquicos ou clientes.

Em síntese, a saúde no trabalho é expressão de um estado disposicional caracterizado pelo equilíbrio marcado pela vivência de prazer e de sofrimento, pela utilização de mecanismos capazes de mobilizar os trabalhadores em busca de uma relação mais gratificante no trabalho e, ainda, pela dinâmica do reconhecimento que se apresenta como elemento essencial no processo de construção da identidade do trabalhador no campo social.

Fundamentado nos pressupostos teóricos da psicodinâmica do trabalho, esse artigo apresenta estudo conduzido em uma central de atendimento ao público com o objetivo de investigar a saúde psíquica destes trabalhadores. O trabalho de atendimento ao público, segundo Ferreira (2000), é de natureza complexa, uma atividade social mediadora pela qual coloca-se em cena a interação de diversos indivíduos em um contexto específico que procura responder a diferentes necessidades. Uma atividade que possibilita às organizações a redução de custos e a facilidade de atendimento ao consumidor pela minimização da interação face a face. Compreende postos de trabalho de atendimento ao cliente por terminais de computadores e aparelhos telefônicos. Os trabalhadores, geralmente, são submetidos a uma série de mecanismos de controle, tais como controle do tempo, do comportamento, do volume e da qualidade dos serviços realizados como também dos resultados alcançados. Devem apresentar um perfil caracterizado, como salienta Higgs (2004), por habilidades tais como de auto-consciência, resiliência emocional, motivação, raciocínio rápido, concentração, memória, capacidade de lidar com variações de humor dos clientes, situações constrangedoras e exigências afetivas. 
Estudos empíricos sobre a relação saúdetrabalho em centrais de teleatendimento, tendo a ergonomia como aporte teórico, revelam que os trabalhadores dessa profissão vivenciam contexto de serviço com aspectos indicadores da vivência de sofrimento psíquico no trabalho. Apontam que a atividade básica do teleatendente é a de controlar o humor do usuário pelo manejo da informação, em um contexto de trabalho caracterizado por: mecanismos de controle interno e externo; falta de autonomia, de variedade de tarefas, de feedback e de apoio social; deficiências na infra-estrutura da informação; falta de treinamento; alta rotatividade; excessiva padronização das tarefas; fadiga física, estresse moral, criatividade limitada, caráter paradoxal do trabalho que valoriza, excessivamente, a quantidade de atendimentos em detrimento da qualidade, apesar do objetivo explícito da atividade ser a satisfação do cliente; organização do trabalho rígida, sobrecarga de trabalho, condições de trabalho, na maioria das vezes, precárias, e relações de trabalho empobrecidas (ABRAHÃO; TORRES; ASSUNÇÃO, 2003; CLARO; CRUZ; SARTORELLI, 2003; FERNANDES et al, 2002; FREIRE, 2002; SILVA et al, 2004; TORRES, 2001; VILELA; ASSUNÇÃO, 2004).

O modelo de investigação adotado no estudo foi delineado a partir do pressuposto de que o contexto de serviço de uma central de teleatendimento constitui variável antecedente à vivência de prazer e sofrimento no trabalho e a presença de sintomas físicos e psicossociais relacionados ao trabalho; a vivência de prazer e a de sofrimento são mediadoras do processo de adoecimento no trabalho; estratégias de mediação individual e coletiva figuram como o modo pelo qual os teleatendentes lidam com o sofrimento para conter o aparecimento de sintomas físicos e psicossociais e para a busca de prazer no trabalho. No estudo, o contexto de serviço foi compreendido como o lugar material, organizacional e social onde se opera a atividade de trabalho e as estratégias individuais e coletivas de mediação utilizadas pelos trabalhadores na inter-relação com a realidade de trabalho, composto pelas dimensões: organizações do trabalho, condições de trabalho e relações sociais de trabalho e as vivências de prazer e de sofrimento no trabalho como resultantes de três diferentes dimensões interligadas e coexistentes: a subjetividade do trabalhador - sua história de vida, desejos e necessidades particulares; o contexto de trabalho - imposições de eficácia, normas, padrões de conduta e condições de trabalho; e a coletividade - relações entre iguais, entre a hierarquia, convivência social no trabalho. Riscos de adoecimento decorrem do contato do trabalhador com situações críticas de trabalho, originando sintomas físicos e psicossociais. Sintomas físicos relacionam-se a dores no corpo e a distúrbios biológicos; sintomas psicológicos a sentimentos negativos em relação a si mesmo e à vida em geral, e sintomas sociais ao isolamento e a dificuldades nas relações familiares e sociais.

\section{Procedimentos Metodológicos}

O estudo, de caráter descritivo e explicativo, utilizou abordagens metodológicas de natureza qualitativa e quantitativa com o objetivo de compreender a dinâmica de trabalho de uma central de teleatendimento. Os instrumentos quantitativos permitiram mapear a amostra quanto à vivência de prazer ou de sofrimento e à presença de sintomas físicos e psicossociais relacionados ao trabalho bem como investigar a utilização de estratégias de mediação individuais e coletivas. Os instrumentos de natureza qualitativa possibilitaram caracterizar o contexto de serviço da central de teleatendimento e aprofundar a investigação de resultados obtidos pelos instrumentos quantitativos.

\subsection{Universo da pesquisa}

O estudo foi realizado com teleatendentes de um setor de faturas de uma empresa multinacional prestadora de serviços de central de atendimento a uma empresa de telefonia fixa; setor responsável pelo recebimento de ligações relativas à contestação e retificação de contas telefônicas. Os dados foram coletados na filial de Goiânia - GO, filial que atende aos estados do Acre, Tocantins, Rondônia, Mato Grosso, Mato Grosso do Sul, Goiás, Paraná, Santa Catarina, Rio Grande do Sul e Distrito Federal. A operadora de telefonia fixa fornece os equipamentos, espaço físico, procedimentos, normas e roteiros para a realização do teleatendimento e a empresa terceirizada realiza a gestão da produção, da qualidade e da mão-deobra da central de atendimento.

Todos os meses, com base no fluxo de clientes atendidos no mês anterior e dos indicadores de nível de serviço definidos pela Anatel, a empresa dimensiona a mão de obra e os padrões de atendimento, fato que resulta em mudanças mensais no número de profissionais, alterações no horário de trabalho dos teleatendentes e na revisão de procedimentos de trabalho. A jornada semanal de trabalho é de 36 horas, de segunda a sábado, e a diária de seis horas. Há dois intervalos de 15 
minutos para lanche e ginástica laboral. Horas extras são realizadas aos domingos e feriados.

\subsection{Participantes}

A amostra utilizada no estudo foi determinada aleatoriamente, de um universo de 612 teleatendentes - 406 do gênero feminino e 206 do gênero masculino -, por convite dirigido aos teleatendentes que estavam trabalhando nos dias da coleta de dados, sendo a participação em ambas as etapas de coleta de dados voluntária.

A primeira etapa da coleta de dados investigação quantitativa - realizou-se pela participação de 396 teleatendentes - 65\% do universo investigado; e, a segunda - investigação qualitativa -, pela participação de nove teleatendentes, subdivididos em dois grupos, o primeiro com quatro participantes e o segundo com cinco.

Os dados da amostra indicaram que a proporcionalidade em relação ao número de teleatendentes da população investigada foi preservada, ou seja, 63,9\% da amostra era do sexo feminino; 71,4\% pertencia à faixa etária entre $18 \mathrm{e}$ 26 anos e 22,7\% entre 27 e 35 anos; 75,9\% era solteira; $48,8 \%$ possui escolaridade equivalente ao ensino médio completo e $44,6 \%$ ao ensino superior incompleto e $64,3 \%$ da amostra tinha menos de dois anos de trabalho na empresa.

\subsection{Instrumentos}

No estudo foram empregados como instrumentos de coleta de dados: observação livre, com o objetivo de obter informações iniciais sobre o contexto e condições de trabalho; Escala de Prazer-Sofrimento no Trabalho - EPST - escala de freqüência do tipo Likert de 5 pontos que investiga quatro fatores, dois relacionados à vivência de prazer no trabalho - realização profissional e liberdade de expressão e dois à de sofrimento esgotamento emocional e falta de reconhecimento (MENDES et al, 2005); Escala de Sintomas Relacionados ao Trabalho - ESRT - escala do tipo Likert de 5 pontos que avalia o grau da presença de sintomas psicológicos, sociais e sintomas físicos decorrentes do confronto com o contexto de trabalho (MENDES et al, 2005) e entrevista coletiva semi-estruturada com o objetivo de analisar as vivências subjetivas e as articulações do singular e do coletivo de trabalho; particularmente de investigar como os teleatendentes percebiam o contexto de serviço da central de atendimento e de analisar a relação entre vivências de prazersofrimento, sintomas físicos e psicossociais e as estratégias de mediação individuais e coletivas utilizadas pelos teleatendentes para lidar com o sofrimento no trabalho.

\subsection{Procedimentos}

A coleta de dados foi realizada em três etapas. $\mathrm{Na}$ primeira delas procedeu-se, por doze horas, a observação simples, total de horas distribuído em três períodos distintos, cada um deles compreendendo o início e o final de um mês do ano. Na segunda, foram aplicadas, coletivamente, as escalas EPST e ESRT e na terceira, realizadas as entrevistas coletivas com teleatendentes voluntários que participaram da coleta de dados quantitativa.

\subsection{Metodologia de análise dos dados}

Os dados quantitativos foram analisados com auxílio do aplicativo SPSS, versão 12.0. Para interpretação dos dados empregou-se estatística descritiva e inferencial - Anova - para análise dos dados demográficos e dos fatores das escalas e Correlação de Pearson para análise de correlações entre os fatores das escalas EPST e ESRT. Os dados qualitativos foram analisados por meio de análise de conteúdo do tipo categorial temática (BARDIN, 1977).

\section{Análise dos Dados}

A análise quantitativa dos dados obtidos pela aplicação da ESPT revelou que os teleatendentes apresentavam vivências moderadas de prazersofrimento no trabalho, com predomínio das vivências de prazer, quadro que sugere o uso de estratégias de mediação defensiva pelo grupo de trabalhadores uma vez que as médias dos fatores de vivência de sofrimento apresentaram pontuação próxima à dos fatores relacionados à vivência de prazer. Dentre as médias alcançadas, em relação à vivência de prazer no trabalho, destacam-se, pelos maiores escores, às relativas aos itens identificação com as tarefas que realiza e solidariedade com os colegas, resultado que sinaliza o significado do trabalho para a categoria profissional e a importância do coletivo de trabalho como viabilizador das vivências de prazer no trabalho, e, pelos menores escores, os itens orgulho pelo trabalho que realiza e liberdade para dizer o que pensa no local de trabalho.

Em relação à vivência de sofrimento, os resultados obtidos revelaram que os teleatendentes vivenciavam moderadamente a percepção de estresse no trabalho e o sentimento de indignação 
devido à falta de reconhecimento no trabalho e que eles possuíam baixa percepção do sentimento de inutilidade e desvalorização, dados coerentes aos altos escores obtidos no item identificação com as tarefas que realiza.

Quanto às diferenças entre as variáveis demográficas e os fatores da ESPT, identificados pelo teste de Anova, os resultados obtidos revelaram que apenas o tempo de trabalho na empresa influenciava a percepção de vivência de realização profissional - os teleatendentes com mais tempo de empresa apresentaram menor percepção de realização profissional.

Os resultados obtidos pela aplicação da ESRT evidenciaram maior média para o fator sintomas físicos, seguido pelo fator sintomas psicológicos e pelo fator sintomas sociais - médias moderadas. Quanto às médias obtidas por item, os resultados revelaram maiores médias nos itens dores nas costas, irritação com tudo e dificuldades para tomar decisões na vida pessoal, e, menores médias, nos itens distúrbios respiratórios, dificuldade para fazer amigos e agressividade desmedida, dados que sugerem serem a monotonia e a robotização da tarefa evocadores de agressividade neste grupo de trabalhadores. O teste de Anova não revelou diferenças significativas entre as médias das variáveis demográficas com os fatores da escala ESRT.

As correlações entre os fatores da EPST e os da ESRT apontaram correlação fraca entre o fator liberdade de expressão da EPST e os fatores da ESRT; correlação média entre o fator falta de reconhecimento e realização profissional e forte correlação entre o fator esgotamento profissional, sinal de que os teleatendentes estão sujeitos ao risco de ocorrência de sintomas psicológicos, físicos e sociais quanto maior for a vivencia de esgotamento profissional. Observou-se, no entanto que, apesar de o fator sintomas físicos ter apresentado a maior média dentre os fatores da ESRT, a correlação mais forte entre os sintomas relacionados ao trabalho e os fatores da ESPT está relacionada ao fator sintomas psicológicos, resultado que sinaliza a demanda afetiva do trabalho de atendimento ao público.

A análise qualitativa dos dados resultou em cinco categorias empíricas. A primeira delas, denominada "O atendimento é sempre a mesma coisa, a gente vai enfadando" revelou uma organização do trabalho orientada de acordo com princípios predominantemente tayloristas, tarefa é repetitiva, atendimento é robotizado, normas rígidas e explícitas e controles realizados por uma diversidade de pessoas e instituições. A constante pressão no trabalho, aliada a rigidez de procedimentos, normas, controle e o caráter repetitivo do trabalho mostrou-se fonte de sofrimento.

A segunda categoria - "A empresa não tem a preocupação de fidelizar os funcionários" demonstrou que a organização não oferece suporte organizacional suficiente para que o trabalho possa ser realizado se forma eficaz - faltam instrumentos, equipamentos, informações para o telatendente e o cliente, precariedade do ambiente físico e de políticas de gestão de pessoas, características comuns a organizações tercerizadas.

A terceira categoria, denominada "O que é imprevisível é o temperamento do cliente" revela a existência de relação amistosa entre pares e supervisores e relação ambivalente entre teleatendentes e clientes, relação que é fonte de prazer quando os profissionais são elogiados e fonte de sofrimento quando são maltratados. Por sua vez, a quarta categoria - "O que motiva a gente, além da necessidade é encontrar os colegas de trabalho" - sugere que o motivo principal da permanência dos teleatendentes na empresa parece ser a necessidade de sobrevivência e que o contexto de trabalho gera sentimentos contraditórios, o que leva os trabalhadores a terem consciência de que é preciso ser equilibrado para trabalhar naquele contexto de trabalho. Observa-se o uso de estratégias defensivas, de compensação e operatórias. Por fim, a última categoria - "Depois que eu entrei aqui, é direto dor de cabeça" expressa os principais sintomas relacionados ao trabalho, cujo aparecimento é favorecido pelo contexto mecanicista de trabalho, aliado à precariedade das condições de trabalho, à natureza repetitiva e sedentária do trabalho e à grande demanda psicológica advinda da relação com o cliente.

A partir dos resultados, pode-se inferir que o trabalho de teleatendimento qualifica-se por aspectos característicos a uma organização do trabalho tipicamente taylorista, à vivência de sofrimento psíquico no trabalho e a riscos de adoecimento: rotina de trabalho repetitiva, padronizada, com procedimentos e normas que mudam constantemente; trabalho realizado sob pressão, com monitoramento constante, intensificado pelo uso de aparto tecnológico; uso de fraseologias que não exprimem a personalidade dos teleatendentes e que acarretam em alienação. Os aspectos críticos à vivência de sofrimento e aos riscos de adoecimento parecem advir dos mecanismos de controle de tempo, de comportamento, do volume e da qualidade dos 
serviços realizados bem como do caráter eminentemente repetitivo das atividades. Admite-se que a vivência de sofrimento advenha ainda da subtração do trabalho e do seu saber intelectual.

A terceirização do serviço, fato que impõe aos trabalhadores a pratica de baixos salários, a inexistência de uma política efetiva de valorização dos trabalhadores, a substituição do pagamento de horas extras por banco de horas, o desinteresse em manter o profissional na empresa insuficiência da política de gestão de pessoas e suporte organizacional, parece acentuar a vivência de sofrimento no trabalho e intensificar o processo de precarização das relações de trabalho.

Por sua vez, a prevalência da vivência de prazer no trabalho parece ser resultante da identificação do atendente com as suas atividades de trabalho e da presença de um contexto de trabalho que propicia a construção de relações intersubjetivas de amizade, e solidariedade com os pares, de melhoraria das habilidades interpessoais pelo contato com uma diversidade de clientes e de reconhecimento do trabalho pelos pares. No entanto, o reconhecimento do trabalho pelos clientes, frente à natureza conflituosa da relação existente entre atendente/cliente, atua tanto como fonte da vivência de prazer como da de sofrimento.

Vale ressaltar que quanto maior a percepção de pouca realização profissional, falta de reconhecimento do trabalho realizado e de acentuado esgotamento profissional, maior a presença de acometimento de doenças do trabalho, principalmente as de natureza física e psicológica, como Dort, estresse e depressão. Apesar da existência de cooperação e de solidariedade no coletivo de trabalho, fonte de vivência de prazer, o contexto de serviço não oferece margem de liberdade para que os trabalhadores, em conjunto, possam ressignificar o sofrimento e fazer a gestão das contradições do trabalho para transformá-lo em fonte de prazer e de saúde.

Diante de tais resultados é factível inferir que os teleatendentes trabalham mesmo expostos ao sofrimento e aos riscos de adoecimento devido à eficácia de estratégias de mediação defensivas construídas pelo coletivo de trabalho para mitigar o sofrimento, estratégias de negação, racionalização, de compensação e de sobrevivência.

\section{Conclusão}

Os dados empíricos evidenciam que o trabalho de teleatendimento, realizado em uma organização do trabalho com características tipicamente tayloristas, favorece o processo de adoecimento, principalmente físico e psíquico. Relações socioprofissionais com os clientes, mesmo de caráter ambivalente, fonte de prazer e de sofrimento, são propiciadoras do aparecimento de sintomas psicológicos relacionados ao trabalho. Paralelamente, a rígida estrutura de trabalho, a pressão por resultados quantitativos e qualitativos, a sobrecarga de trabalho, a realização de tarefas repetitivas e o monitoramento constante, associados à falta de reconhecimento do trabalho ou à um reconhecimento contraditório originado na interrelação atendente-cliente favorecem o adoecimento.

A vivência de prazer, neste contexto de serviço, é fruto das relações estabelecidas com os pares e com os supervisores, da identificação com as tarefas e do reconhecimento do trabalho pelos clientes, pelos elogios esporádicos. Estratégias de mediação, defensivas e de compensação, exercem papel fundamental para a contenção do processo de adoecimento.

A realização desse estudo permitiu investigar os riscos de adoecimento presentes no contexto de uma central de atendimento e o papel das estratégias de mediação como fator relevante de contenção e manutenção da saúde de teleatendentes. O estudo, ao aliar instrumentos de natureza quantitativa e qualitativa, permite maior compreensão da dinâmica da inter-relação trabalho-saúde e contribui para evidenciar a necessidade de que as empresas do ramo de central de teleatendimento ofereçam suporte organizacional e políticas de gestão de pessoas que contemplem a natureza do trabalho e a saúde dos trabalhadores envolvidos.

\section{Referências}

ABRAHÃO, J. I.; TORRES, C.; ASSUNÇÃO, A. A. Penosidade e estratégias de atenuação do risco: o caso das telefonistas de uma instituição pública. Estudos Goiânia, v. 30, n. 1, p. 61-84, 2003.

BARDIN, L. Análise de conteúdo. Lisboa: Edições 70, 1977.

BUSCATTO, M. Les centres d'appels, usines modernes? Les rationalisations paradoxales de la relation téléphonique: call centers, modern factories? The paradoxical rationalization of telephonic relations. Sociologie du travail, v. 44, n. 1, p. 99-117. 2002.

CLARO, M. M. F., CRUZ, R. M.; SARTORELLI, J. $B$. Diagnóstico do trabalho e repercussões sobre a saúde dos trabalhadores de centrais telefônicas. Psicologia Argumento, v. 21, n. 33, p. 55-60, 2003. 
DEJOURS, D. Addendum, da psicopatologia à psicodinâmica do trabalho, In: LANCMAN, S.; SZNELWAR, L. I. (Orgs.). Christophe Dejours: da psicopatologia à psicodinâmica do trabalho. Brasília: Paralelo15/FIOCRUZ, 2004. p. 47-104.

DEJOURS, C. Conferências brasileiras: identidade, reconhecimento e transgressão no trabalho. São Paulo: Fundap/FGV, 1999.

FERNANDES, J. D. et al. Saúde mental e trabalho feminino: imagens e representações de enfermeiras. Revista Latino Americana de Enfermagem, v. 10, n. 2, p. 199-206. 2002.

FERREIRA, M. C. Serviço de atendimento ao público: o que é? Como analisá-lo? Esboço de uma abordagem teórico-metodológica em ergonomia. Revista Multitemas, n. 16, p. 128-144, 2000.

FERREIRA, M. C.; MENDES, A. M. Trabalho e riscos de adoecimento: o caso dos auditoresfiscais da previdência social brasileira. Brasília: Ler, Pensar, Agir, 2003.

FREIRE, O. N. "Ser atendente a vida toda é humanamente impossível": serviço de teleatendimento e custo humano do trabalho. 2002. 140 f. Dissertação (Mestrado em Psicologia) Universidade de Brasília, Brasília, 2002.

HIGGS, M. A study of relationship between emotional intelligence and performance in UK call centres. Journal of Managerial Psychology, v. 19, n. 4, p. 442-454, 2004.

MENDES, A. M. Comportamento defensivo: uma estratégia para suportar o sofrimento no trabalho. Psicologia Fortaleza, v. 13/14, n. 1/2, p. 27-32, 1996.

MENDES, A. M. Cultura organizacional e prazersofrimento no trabalho: uma abordagem psicodinâmica. In: TAMAYO, A. (Org.). Cultura e saúde nas organizações. Porto Alegre: Artmed. 2004. p. 59-76.

MENDES, A. M. et al. Validação do inventário de trabalho e riscos de adoecimento - ITRA. In: CONGRESSO NORTE NORDESTE DE PSICOLOGIA, 4., 2005, Salvador. Anais... Salvador: Universidade Federal da Bahia, 2005.

TORRES, C. A atividade nas centrais de atendimento: outra realidade, as mesmas queixas. 106 f. 2001. Dissertação (Mestrado em Psicologia) Instituto de Psicologia, Universidade de Brasília, Brasília, 2001.

SILVA, J. R. G. et al. Operadores de call center: inconsistências e desafios da gestão de pessoas. In: ENCONTRO DA ASSOCIAÇÃO NACIONAL DE PÓS-GRADUAĈÃO E PESQUISA EM

ADMINISTRAÇÃ̃O, 26., 2004, Curitiba. Anais... Rio de Janeiro: ANPAD, 2004.

VILELA, L. V. O.; ASSUNÇÃO, A. A. OS mecanismos de controle da atividade no setor de teleatendimento e as queixas de cansaço e esgotamento dos trabalhadores. Cadernos de Saúde Pública, v. 20, n. 4, p. 1069-1078, 2004.

ZARIFIAN, P. Comunicação e subjetividade nas organizações. In: DAVEL, E.; VERGARA, S. (Orgs.). Gestão com pessoas e subjetividade. São Paulo: Atlas, 2001. p.151-170. 